\section{Mask CPAP during neonatal transition: too much of a good thing for some term infants?}

\author{
Christian F Poets, ${ }^{1}$ Mario Rüdiger ${ }^{2}$
}

In their quest to optimise treatment strategies, neonatologists may sometimes be tempted to extrapolate results obtained during the care of very immature to more mature neonates, assuming that what is right in the former, most fragile infants cannot be wrong in the latter. A study from Tokyo, however, highlights the potential risks associated with such generalisations: in an audit of neonatal care, Hishikawa $e$ $a l^{1}$ noted that, following the adoption of new guidelines issued by the Japanese resuscitation council, the proportion of term neonates receiving continuous positive airway pressure (CPAP) via face mask increased from $1.7 \%$ to $11.1 \%$. This shift in clinical practice was associated with a doubling of the rate of infants with a diagnosis of pulmonary air leak (from $1.0 \%$ to $1.8 \%$ ). Part of this increase may have been due to an increase in the number of infants receiving chest $\mathrm{X}$-rays ( $8 \%$ before vs $17 \%$ after the new guideline), that is, a diagnostic shift, but this is unlikely as the latter rise was not disproportionate to the increase in air leaks. ${ }^{1}$

Faced with these data from a retrospective audit, is it plausible that the observed association is true, that is, may there indeed be a relationship between CPAP use and pulmonary air leak? More than 30 years ago, Vyas et al measured pulmonary pressures in term neonates during the first postnatal minutes. They found a median pressure of $40 \mathrm{~cm} \mathrm{H}_{2} \mathrm{O}$ (range 12-80) during inspiration and $72(12-120) \mathrm{cm}$ $\mathrm{H}_{2} \mathrm{O}$ during expiration. ${ }^{2}$ Given these physiological data, one could argue that an increase of 4-6 cm H $\mathrm{H}_{2} \mathrm{O}$, as typically used during CPAP administration, is unlikely to have a deleterious effect. On the other hand, two large randomised controlled

\footnotetext{
${ }^{1}$ Department of Neonatology, Tübingen University Hospital, Tübingen, Germany; ${ }^{2}$ Division of Neonatology and Paediatric Intensive Care, Department of Paediatrics, Universitätsklinikum Carl Gustav Carus, Technische Universität Dresden, Germany

Correspondence to Professor Christian F Poets, Department of Neonatology, Tübingen University Hospital, Calwerstr. 7, Tübingen 72076, Germany; christian-f.poets@med.uni-tuebingen.de
}

trials in preterm infants also noted an increase in air leaks in association with application of CPAP: Buckmaster $e a^{3} l^{3}$ randomised 300 infants born at $>30$ weeks' gestation with respiratory distress to either CPAP or headbox oxygen and found that three times more infants randomised to CPAP developed pneumothorax (5/149 $(3.4 \%)$ vs $14 / 151 \quad(9.3 \%), \quad p=0.06)$. However, $23 \%$ of those randomised to CPAP vs $40 \%$ of those in the headbox oxygen group were classified as treatment failure, that is, required $\geq 50-60 \%$ oxygen, had a $\mathrm{pCO}_{2}>60 \mathrm{~mm} \mathrm{Hg}$ or a $\mathrm{pH}<7.25$ and/or needed transfer to a higher-level neonatal unit, so there clearly was also a benefit from CPAP in these preterm infants. While the increase in pneumothorax rates was not significant in the latter study, it did reach significance in the Cochrane analysis on this issue, which reported more than a doubling in the risk of pneumothorax in preterm infants randomised to nasal CPAP versus non-ventilation (relative risk 2.64, 95\% CI 1.39 to 5.04$){ }^{4}$

Shortly afterwards, the Continuous Positive Airway Pressure or Intubation at Birth study group reported similar results for their much more immature infants: they randomised infants of 25-28 weeks' gestation to intubation and surfactant versus CPAP only, and while there was no significant difference in the primary outcome, death or bronchopulmonary dysplasia, pneumothorax occurred three times more often in infants randomised to CPAP than in those receiving early intubation and surfactant (3\% vs $9 \%$, $\mathrm{p}<0.001)$. Yet, the latter results were attributed, at least in part, to the fact that intubation criteria were rather restrictive in infants randomised to CPAP, that is, they were only intubated if inspired oxygen concentration exceeded $60 \%$ or $\mathrm{pCO}_{2} 60 \mathrm{~mm} \mathrm{Hg}$, and average CPAP pressures were comparatively high (starting at $8 \mathrm{~cm} \mathrm{H}_{2} \mathrm{O}$ ). ${ }^{5}$ This may also explain why these results were not confirmed by the Surfactant, Positive Pressure, and Oxygenation Randomized Trial investigators, who studied a similar patient population, but had more liberal intubation criteria. ${ }^{6}$

Taking the above data from preterm and those from Hishikawa $e t a l^{1}$ on term infants together, it appears that CPAP administration in the delivery room may be associated with an increased risk of developing pulmonary air leak. In term infants, this may be particularly relevant to those born after elective caesarean section, as this is associated with an increased risk of a disturbed pulmonary adaptation. With an increasing number of elective C-sections, neonatologists face the problem of how to treat these infants. The liberal use of oxygen is not only associated with delayed onset of spontaneous breathing but also with an increased mortality. The risks of intubation and mechanical ventilation are well known; this seems not the appropriate treatment in spontaneously breathing infants with only mild respiratory distress. Observation only may result in a deterioration of respiratory distress.

Research on delivery room management has focused mainly on preterm infants, the needs of the majority, that is, (near-) term infants have been somewhat neglected. Konstantelos et $a l^{7}$ recently reported that $25 \%$ of term infants delivered by C-section received some form of respiratory support in the delivery room. This, and the sixfold increase in the use of positive pressure support following the revision of neonatal guidelines reported by Hishikawa et $a{ }^{1}{ }^{1}$ raises the question if all these infants would have only recovered with such support, or may these high rates also reflect a trend towards overtreatment? Has the apparent ease of use of the t-piece ventilator for neonatal respiratory support led to an increased readiness to use it, without waiting whether an infant recovers spontaneously? There is an urgent need to base therapeutic interventions on sound scientific data. A first step is an observational study such as the present report from Tokyo, but what we also need are prospectively collected data that do not only determine criteria for infants truly requiring respiratory support but will also provide data concerning the optimal treatment of respiratory distress in term infants. In the meantime, we may be well advised to remain judicious when faced with the decision to start positive pressure support in a term neonate. As with other neonatal therapies, this is an intervention that may have serious side effects.

Contributors CFP wrote the initial draft. MR critically reviewed the manuscript and added relevant intellectual content.

Competing interests None. 
Provenance and peer review Commissioned; internally peer reviewed.

To cite Poets CF, Rüdiger M. Arch Dis Child Fetal Neonatal Ed 2015;100:F378-F379.

Received 23 March 2015

Accepted 24 March 2015

Published Online First 15 April 2015

\section{Linked}

http://dx.doi.org/10.1136/fetalneonatal-2014307891
Arch Dis Child Fetal Neonatal Ed 2015;100:F378F379. doi:10.1136/archdischild-2015-308236

\section{REFERENCES}

1 Hishikawa K, Goishi K, Fujiwara T, et al. Pulmonary air leak associated with CPAP at term birth resuscitation. Arch Dis Child Fetal Neonat Ed 2015; 100:382-7.

2 Vyas H, Milner AD, Hopkins IE. Intrathoracic pressure and volume changes during the spontaneous onset of respiration in babies born by cesarean section and by vaginal delivery. J Pediatr 1981;99:787-91.

3 Buckmaster AG, Arnolda G, Wright IM, et al. Continuous positive airway pressure therapy for infants with respiratory distress in non tertiary care centers: a randomized, controlled trial. Pediatrics 2007;120:509-18.
4 Ho JJ, Henderson-Smart DJ, Davis PG. Early versus delayed initiation of continuous distending airway pressure for respiratory distress syndrome in preterm infants. Cochrane Database Syst Rev 2002;(2): CD002975.

5 Morley CJ, Davis PG, Doyle LW, et al. Nasal CPAP or intubation at birth for very preterm infants. $N$ Engl J Med 2008:358:700-8.

6 Finer NN, Carlo WA, Walsh MC, et al. Support Study Group of the Eunice Kennedy Shriver NICHD Neonatal Research Network. Early CPAP versus surfactant in extremely preterm infants. N Engl J Med. 2010;362: 1970-9.

7 Konstantelos D, Ifflaender S, Dinger J, et al. Analyzing support of postnatal transition in term infants after c-section. BMC Pregnancy Childbirth 2014;14:225. 